\title{
Enoturismo: o vinho como produto turístico
}

\author{
Wine Tourism: wine as a tourist product
}

\section{Eliza Bianchini Dallanhol Locks' \\ Hernanda Tonini ${ }^{2}$}

\begin{abstract}
RESUMO: O turismo possui diferentes faces objetivando satisfazer um número cada vez maior de pessoas. Uma dessas faces, de recente e notável crescimento, busca no gosto pelo vinho e por sua cultura a força capaz de gerar o enoturismo. Por meio de bibliografia existente, entrevistas e visitas técnicas, foi realizado um levantamento dos aspectos gerais das principais localidades enoturísticas no mundo, possibilitando aprofundar o significado e a importância da atividade turística associada ao vinho, que acompanha o homem desde a Antiguidade. O prazer proporcionado ao degustar um vinhovai muito além dos sentidos físicos; quando associado ao seu entorno, torna-se um momento lúdico, envolto em idéias e sentimentos. $O$ enoturismo não é apenas mais uma ramificação da indústria turística, mas sim uma oportunidade de resgatar a história da humanidade, seu valor e sua simbologia.
\end{abstract}

PALAVRAS-CHAVE: enoturismo; vinho; produto turístico; motivação; cultura.

ABSTRACT: Tourism involves a wide range of components that aim to please an ever-growing number of people. One of these components that

1. Mestre em Economia e Gestão do Turismo pelo Centro Internacional de Estudos da Economia Turística - CISET, Ca'Foscari - Itália; bacharel em Turismo e Hotelaria. Professora do Curso de Turismo da Universidade do Sul de Santa Catarina - unisul. Contato: Campus Tubarão - Av. José Acácio Moreira, 787 - Caixa Postal 370 - 88704-900 - Tubarāo - sc; e-mail: eliza@unisul.br.

2. Pós-graduanda MBA em Gestão Empresarial na Fundação Getúlio Vargas - sC; bacharel em Turismo. Contato: Est. Manoel Leôncio de Souza Brito, 46 - 88052-400 - Florianópolis, SC; e-mail: htonini@hotmail.com. 
have recently had a remarkable growth is the interest in wine tasting and its culture to foster Wine Tourism that is relating wine production to a cultural, environmental, historical, and social context. Due to bibliographical references, interviews, and scientific magazines, it was possible to conduct a survey regarding general information on the most important wine tourist locations in the world. This study allowed a deeper understanding of the importance and meaning of tourism associated to winery, an activity that has been related to man since ancient times. Pleasure associated to wine tasting surpasses physical senses; it certainly becomes a joyful moment, inspired by ideas and feelings, when associated to wine surroundings. Wine Tourism is not simply a branch of the tourism industry, but also a possibility to recover the history of humankind, as well its symbols, and values.

KEYWORDS: wine tourism; wine; tourist products; motivation; culture.

\section{Introdução}

O enoturismo, turismo de vinhos ou turismo enológico, como também é conhecido, é uma recente atividade caracterizada pelo deslocamento de pessoas a localidades que possuem tradição na produção de uvas e fabricação de vinhos, bem às regiões emergentes da atualidade. Durante o período dessas visitações, outros produtos e serviços são demandados e, conseqüentemente, oferecidos pela comunidade autóctone, gerando mais uma oportunidade à grandiosa indústria turística.

No momento em que um indivíduo se afasta temporariamente de sua residência fixa, apresenta a necessidade de um conjunto que satisfaça suas carências, como alimentação, abrigo, higiene e lazer, entre outras. Dessa forma, no entorno das localidades enoturísticas desenvolve-se uma rede de hospedagem, de gastronomia, de lazer e de artesanato associada a uma infra-estrutura essencial, constituindo um produto turístico. O motivo principal do enoturista concentrase na degustação de vinhos e nas visitações às cantinas, podendo conhecer e até mesmo participar da elaboração de vinhos.

Em vista do relevante crescimento desse segmento turístico, e acompanhando as alterações no perfil do turista, o presente trabalho objetiva conceituar o enoturismo, seus benefícios e a atividade no mundo e no Brasil.

Para realizar o estudo, foi utilizado o tipo de pesquisa descritiva, demonstrando sua importância por meio de fatos concretos, e também do tipo bibliográfica, buscando nortear o leitor sobre o conceito de enoturismo e sobre o porquê de seu acontecimento. Foram pesquisados periódicos, livros e artigos disponíveis na rede mundial de computadores, entrevistas com profissionais do ramo vinícola, apreciadores da bebida e levantamento de dados de diferentes rotas de vinho no mundo.

De forma a nortear o leitor sobre o tema, o presente artigo está organizado em quatro partes. A introdução possibilita um breve entendimento do enoturismo, identificando os objetivos e métodos da pesquisa.

O tópico "Enoturismo: o vinho como produto turístico" é dedicado à exposição do assunto, abordando os diferentes aspectos encontrados sobre a atividade enoturística no Brasil e no mundo, além de relatar as informações obtidas durante entrevistas.

A conclusão é encontrada apresentando todas as considerações sobre o enoturismo, criadas a partir do aprofundamento no tema.

As diferentes fontes bibliográficas citadas no corpo do trabalho encontram-se referenciadas no quarto tópico, dando à pesquisa a comprovação científica.

\section{Enoturismo: o vinho como produto turístico}

\section{Conceituando enoturismo}

De acordo com Hall et al. (2000), o vinho e o turismo estão ligados há muito tempo, mas apenas recentemente têm sido reconhecidos por governantes, pesquisadores e pela indústria turística. Para o turismo, o vinho é um importante atrativo motivacional. Para a indústria vinícola, o enoturismo é uma forma de construir relações com os clientes, que podem experimentar e conhecer os produtos em sua essência.

Também conhecido como turismo de vinhos ou turismo enológico, o enoturismo teve sua origem em meados da década de 1980, no continente euro$\mathrm{peu}^{3}, \mathrm{e}, \mathrm{embora}$ recente, apresenta futuro próspero. O termo é resultado da união de eno e turismo, sendo que, segundo o Vocabolario Della Língua Italiana, eno deriva do grego oînos e significa vinho.

Enoturismo é um segmento da atividade turística que se fundamenta em viagens que são motivadas por pessoas que apreciam o aroma, o sabor e a degustação de vinhos, bem como a apreciação das tradições e tipicidade das localidades que produzem esse tipo de bebida. ${ }^{4}$

3. Disponível em: <http://www.nolasco.cjb.net>. Acesso em: 16 mai. 2004.

4. Disponível em: <http://www.girus.com.br/viagens/conceitos.php>. Acesso em: 4 jun. 2004 
Para Giovani Valduga ${ }^{5}$, "enoturismo é a atividade turística desenvolvida junto às vinícolas." Ainda na sua visão, é uma forma de trabalhar o turismo de maneira sustentável, considerando que as localidades que o promovem são referência em qualidade de vida.

Segundo o site do Department of the Queensland Government State Development (Departamento do Governo de Queensland para o Desenvolvimento Estadual):

If 'Tourism' is simply the provision of goods and services that attract tourists, then 'Wine Tourism' is the same but has the added influence of wine. Wine Tourism is not only associated with cellar door wineries, rather all business that are involved in the Wine, Tourism and Associated industries with the wine region. This includes accommodation houses, tour operators, gift shops, national parks etc. ${ }^{6}$

Nesta definição é possível perceber onde o vinho se enquadra ao trabalhar em conjunto com o turismo, pois o enoturismo não é visto apenas como uma relação exclusiva com as cantinas, mas com todos os empreendimentos envolvidos com o vinho, com o turismo e com a associação de indústrias da região vinícola.

Es un turismo en el cual los diversos elementos involucrados en el processo de elaboración del vino - bodegas, viñedos y su entorno - se colocan en el centro de la experiencia vacacional. En pocas palabras: es capitalizar en el atractivo turístico de las regiones vitivinícolas como estrategia de ventas y mercado. ${ }^{7}$

Juciane Casagrande, responsável pela área comercial da vinícola Casa Valduga, define o enoturismo como "a junção do turismo ao vinho. Permite ao

5. Entrevista concedida em 22 de maio de 2004 por Giovani Valduga, estudante de turismo da Universidade de Caxias do Sul (UCS), e um dos proprietários da Vallontano Vinhos Nobres, localizada no Vale dos Vinhedos, em Bento Gonçalves, Rio Grande do Sul.

6. "Se o turismo é apenas a provisão de bens e serviços que atraem o turista, o enoturismo é a mesma coisa, sofrendo influência do vinho. Enoturismo não está apenas associado com as cantinas, mas também com todos os negócios envolvidos com o vinho, com o turismo e com as indústrias associadas com a região vinícola. Isto inclui meios de hospedagem, guias, lojas de presentes, parques nacionais etc." (tradução da autora). Disponível em: < http://www.sd.qld.gov.au/dsdweb/htdocs/global/content.cfm>. Acesso em: 1 jun. 2004.

7. "É um turismo em que os diversos elementos envolvidos no processo da elaboração do vinho cantinas, vinhedos e o seu entorno - se colocam no centro da experiência de viagem. Em poucas palavras: é capitalizar o atrativo turístico das regiōes vitivinícolas como estratégia de vendas e de mercado" (tradução da autora). Disponível em: <http://www.vinealis.com/canales $>$. Acesso em: 1 jun. 2004. turista passear, conhecer locais, cantinas, parreirais, o processo de elaboração e degustar vinhos. Enfim, tudo que é ligado ao vinho bem como ao dia-a-dia daqueles que trabalham neste meio."8

Segundo a Australian Wine Industry (Indústria de Vinhos da Austrália), a indústria do turismo e a indústria do vinho estão compartilhando o mesmo objetivo, apresentando aos consumidores a originalidade no local de destino, sejam eles apreciadores de vinho ou turistas. ${ }^{9}$

\section{O enoturismo no mundo}

Da mesma forma que a indústria turística vem sofrendo alterações, o setor vinícola também busca a satisfação de seus clientes. $\mathrm{O}$ aprimoramento do paladar dos consumidores de vinho e as alterações que estão ocorrendo com as preferências do turista estão contribuindo para consolidar o enoturismo, que aos poucos está sendo divulgado, o que cria a necessidade de profissionais preparados para atender o enoturista. Na visão de Pacheco e Silva (2001: 331): "os profissionais da área de serviços turísticos devem, cada vez mais, se adaptar aos novos interesses desse público, buscando conhecimentos que lhes permitam diferenciar e valorizar o seu trabalho".

Ainda sob a ótica de Pacheco e Silva (2001), as visitações organizadas nos roteiros de vinhos em países como França, Itália, Espanha, Portugal e Alemanha são tão ou mais procuradas que as visitações a museus e monumentos. Esses países europeus trabalham sua oferta gastronômica como um atrativo cultural, pois nesta se reflete e concentra a história, a tradição e a evolução desses povos, além de considerarem o vinho um patrimônio cultural, intimamente ligado à sua tradição histórica e à gastronomia. ${ }^{\bullet}$

O Instituto de Turismo de Portugal divulga em seu site as seguintes características para a atividade: "o enoturismo ou turismo vitivinícola concentra, a propósito do vinho, vertentes ambientais, culturais e gastronômicas regionais, e, ainda, diversos outros produtos de que são exemplo o artesanato e o turismo no espaço rural".

Ainda com base nesse instituto, o produto turístico a ser trabalhado são as rotas de vinhos, considerando-as uma forma de diversificar a oferta turística nacional, estimulando a capacidade das cantinas, dos atrativos naturais, etnográficos e culturais. Por meio delas é possível organizar e divulgar o enoturismo, contri-

8. Mensagem recebida pelo endereço eletrônico htonini@hotmail.com, em 16 jun. 2004

9. Disponível em: <http://www.wfa.org.au/projectos/winetourism.html >. Acesso em: 1 jun 2004.

10. Disponível em: <http://www.vinealis.com/canales $>$. Acesso em: 28 mai. 2004. 
buindo para o desenvolvimento local das regiões vitivinícolas e para melhoria das condições de vida da população."

A idéia de trabalhar o vinho como um atrativo cultural e turístico nasceu em 1993, com a criação do Movimento do Turismo del Vino, na Itália. A associação disponibilizou para os turistas um roteiro de visitação às vinícolas, chamado "Cantina Aberta”. Durante esses passeios, enoturistas são guiados por locais previamente estudados, como descoberta de castelos, museus da cultura colonial e visitas aos vinhedos e às cantinas para degustação de vinhos. ${ }^{12}$ Para Karen Gilchrist, "un tour de vinos, antes que todo, es 'el viaje de los sentidos". ${ }^{3}$ A manifestação Cantina Aberta deu origem ao Wine Day (Dia do Vinho), comemorado mundialmente no último domingo do mês de maio.

Segundo informação obtida no site do Departamento do Governo de Queensland para o Desenvolvimento Estadual, dentre os benefícios econômicos e sociais que o enoturismo proporciona às regiões vinícolas e à sua indústria destacam-se o incremento de visitantes e da repetição das visitas; o aumento do período de estada dos turistas e, conseqüentemente, de seus gastos no destino; o acréscimo das vendas no local; e o fato de realçar a satisfação dos turistas por meio da oferta de outras atividades.

Um dos programas de desenvolvimento do enoturismo europeu foi apresentado em 11 de abril de 2003 pela Assembléia das Regiões Vinícolas da Europa (AREV), a Carta do Enoturismo da Europa, que pretende potencializar os diferenciais das regiões com vocação vitivinícola, agrupando todos os envolvidos e permitindo aos enoturistas escolherem seu destino em nível local, regional e nacional. Atualmente existem na Europa 216 rotas de vinhos, subdivididas da seguinte maneira: 98 na Itália, 20 na Eslovênia, 17 na Áustria, 16 na Espanha, 15 na França, 15 na Hungria, 11 na Alemanha, 11 em Portugal, 6 na Grécia, 4 na Croácia, 2 na Suíça e 1 na Eslováquia. ${ }^{14}$

Na Itália, devido à forte tradição vitivinícola, praticamente todas as regiões cultivam a vinha e fabricam vinho, seja através de grandes ou de pequenos produtores. Conforme abordado anteriormente, o país se tornou o berço do enoturismo com a criação da associação Movimento do Turismo del Vino, sem fins lucrativos, responsável pela divulgação das diferentes rotas do vinho existentes ao longo do país, com o objetivo de aumentar o prestígio e melhorar o desenvolvi-

11. Disponível em: $<$ http://www.ifturismo.min-economia.pt $>$. Acesso em: 1 jun. 2004

12. Disponível em: $<\mathrm{http}: / /$ www.movimentoturismovino.it $>$. Acesso em: 2 jun. 2004.

13. "Um tour de vinhos, antes de tudo, é a viagem dos sentidos". Disponível em: <http://www. planetavino.com/navegacion/navegar>. Acesso em: 28 mai. 2004.

14. Disponível em: <http://www.mtvlombardia.it>. Acesso em: 2 jun. 2004. mento econômico das vinícolas. O Movimento do Turismo del Vino possui aproximadamente 900 cantinas cadastradas e tem como objetivo garantir a preservação do meio ambiente e da agricultura de qualidade, promovendo um estilo de vida o mais natural possível, o que se torna um dos atrativos. ${ }^{15}$

A segunda edição da Cantina Aberta, realizada em toda a Itália pelo MTV nos dias 29 e 30 de maio de 2003, foi um sucesso, registrando mais de 1,2 milhão de enoturistas e se firmando como a grande festa do vinho italiano. A manifestação ofereceu aos apaixonados e aos curiosos incansáveis degustações de vinhos combinadas com produtos típicos, expressando as tradições locais, além de promover iniciativas originais como concertos, espetáculos, músicas folclóricas, itinerários naturalistas arqueológicos, mostra de carros antigos e mostras de arte, entre outras. ${ }^{16}$

Para melhor controlar a qualidade da oferta turística, facilitando a divulgação da mesma, a associação criou o Decalogo dell'Accoglienza, envolvendo todas as regiões vitivinícolas que se associaram ao Movimento do Turismo del Vino. Para distinguir o nível de qualidade dos estabelecimentos, a simbologia escolhida foi a folha da vinha: de acordo com os quesitos "espaço e serviço" " "método e pessoas", o estabelecimento recebe a identificação gradativa de três, quatro ou cinco folhas verdes; ou então cinco folhas douradas, quando de máxima qualidade. ${ }^{17}$

Na Austrália, as vinícolas oferecem, além de tours, espaços bem montados aos apreciadores - os chamados cellardoors -, onde se realizam as degustações e se comercializam os produtos com atendimento especializado. Algumas vinícolas também oferecem como atrativo um restaurante com bela vista para os vinhedos. Além disso, a combinação de música e gastronomia, promovida nos jardins, é capaz de atrair 50 mil pessoas em um fim de semana. ${ }^{18}$

Segundo uma pesquisa realizada em 1998, o número de visitantes em todas as vinícolas australianas estava estimado em 3 milhões, sendo que $81,9 \%$ eram turistas nacionais. Os principais motivos apresentados para as visitações foram degustação e compra de vinhos, pois apenas 7\% das vinícolas ofereciam acomodações (Hall et al, 2000).

Segundo o site da Winemaker Federation of Australia - WFA (Federação das Vinícolas Australianas), em 1993, 235 mil turistas estrangeiros visitaram o país. Este número subiu para 456 mil em 1999, sendo que o maior incremento foi

\footnotetext{
15. Disponível em: <http://www.movimentoturismovino.it >. Acesso em: 28 mai. 2004 16. Idem

17. Idem.

18. Disponível em: <http://www.revistadigital.com.br/empresas.asp>. Acesso em: 11 jun. 2004
} 
verificado nas regiões vitivinícolas, que passaram a investir em outros serviços para atender o turista, como alimentação e hospedagem. Para a maioria dos visitantes, a compra de vinhos era a principal motivação. Entre os turistas nacionais, o perfil mais recorrente era de casais sem filhos, entre 40 e 60 anos de idade e com educação superior. ${ }^{19}$

De acordo com o site do Departamento do Governo de Queensland para o Desenvolvimento Estadual, para obter sucesso cada região tem de potencializar seu diferencial. O primeiro passo é desenvolver um plano de compreensão regional sobre o desenvolvimento do turismo, agrupando os produtos, os recursos e as potencialidades de mercado, o que possibilitará o crescimento do turismo de forma sustentável.

\section{O enoturismo no Brasil}

Na concepção de Pacheco (1995), a qualidade dos vinhos brasileiros tem melhorado gradativamente nos últimos anos. Isso é resultado da busca pelo conhecimento por parte dos enólogos responsáveis, dos investimentos em tecnologia européia e americana e da criação de entidades ligadas ao consumidor de vinhos.

Apesar da significativa melhora da qualidade dos vinhos nacionais, o país é o $17^{\circ}$ produtor mundial, e o consumo per capita é inferior a 2 litros/ano, enquanto que na França, maior consumidor de vinhos no mundo, chega a 60 litros/ano. A exceção dessa estatística é a Serra Gaúcha, que consome per capita 30 litros/ano (Braga \& Alzer, 2003).

De acordo com Splendor (2003), o enoturismo no Brasil deve destacar a qualidade e a imagem do vinho nacional, ativar a vida turística da região produtora de uva e vinho, destacar os benefícios da bebida e estimular o seu consumo. Ainda na visão desse autor, os aspectos que atraem o enoturista são os atrativos culturais, os eventos relacionados e as construções.

Ainda sob a ótica de Splendor (2003:38), "[...] o enoturismo engloba toda a área onde a produção industrial e a de competitividade são oferecidas aos consumidores".

Segundo Pacheco e Silva (2001), a expectativa é que o Brasil consolide sua posição entre os vinte maiores produtores de vinho mundiais, captando um número cada vez maior de turistas nacionais e estrangeiros.

João Alexandre Lombardo ${ }^{20}$ identifica a significativa melhora dos vinhos nacionais, que, com a modernização das vinícolas, transformaram-se em pontos

19. Disponível em: <http://www.wfa.org.au>. Acesso em: 1 jun. 2004.

20. João Alexandre Lombardo é jornalista e professor da Universidade do Sul de Santa Catarina. de visitação de turistas e interessados em conhecer melhor os vinhos nacionais e seu modo de produção. Ainda na sua visão:

Na esteira do crescimento do interesse dos brasileiros pelos vinhos, roteiros foram traçados nas regiōes produtoras e uma nova modalidade de turismo começou a ganhar força: o turismo enogastronômico. Além de estimular a produção e o comércio de vinhos nacionais, essa modalidade de turismo abre novas perspectivas para profissionais e empresas de diversas áreas. ${ }^{21}$

Para aumentar a popularidade do vinho no Brasil, foi criado no Rio Grande do Sul o Dia Estadual do Vinho, que será comemorado anualmente no primeiro domingo do mês de junho. A iniciativa partiu de um projeto do deputado Iradir Pietroski (РТВ), aprovado por unanimidade na Assembléia Legislativa e sancionado pelo governador Germano Rigotto em 11 de dezembro de 2003. A celebração já faz parte do calendário anual de eventos do Estado, e acontecerá nessa data não só para divulgar os novos produtos do mercado vinícola, mas também por ser uma época de poucas festas no circuito turístico. Durante o Dia Estadual do Vinho, uma intensa programação artístico-cultural, degustação de vinhos e promoções em hotéis e restaurantes serão disponibilizadas ao turista. ${ }^{22}$

Algumas instituições, como o Banco do Brasil - em parceria com o Banco Nacional de Desenvolvimento Econômico e Social - BNDES, com a Secretaria de Estado da Agricultura e Abastecimento do Rio Grande do Sul - SAA-RS e com o Instituto Brasileiro do Vinho - IBRAVIN -, estão oferecendo incentivos financeiros para desenvolver a vitivinicultura e o enoturismo no Estado, objetivando garantir a competitividade e a sustentabilidade do setor $^{23}$.

Tamanha é a projeção do vinho nacional que a IBRAVIN realizou no mês de março uma licitação para promoção institucional e publicidade do vinho brasileiro, disponibilizando verba de $\mathrm{R} \$ 455$ mil no primeiro semestre, a qual será triplicada para o segundo. ${ }^{24}$

Atualmente, o principal destino dos enoturistas no País é a Serra Gaúcha. Segundo o Guia de Viñas, Bodegas y Vinos da América do Sul (2004: 251), este destino oferece "[...] óptimos y lindos caminos, naturaleza, clima, gente, historia, vinos y grapas hechas por vênetos."25

21. Mensagem recebida pelo endereço eletrônico htonini@hotmail.com, em 22 jun. 2004.

22. Disponivel em: <http://www.ibravin.org.br $>$. Acesso em: 8 jun. 2004.

23. Disponivel em: $<$ http://www.bb.com.br/noticias $>$. Acesso em: 31 mai. 2004.

24. Disponivel em: <http://www.ibravin.org.br/detalhes $>$. Acesso em: 31 mai. 2004.

25. "Otimos e lindos caminhos, natureza, clima, pessoas, história, vinhos e grapas feitas por vênetos" (tradução da autora). 
Ainda segundo esse Guia (2004: 254), a oferta enoturística na Serra Gaúcha supera os demais países latinos, sendo que suas vinícolas estão entre as melhores em termos de tecnologia.

De cara al enoturismo, las bodegas del Valle de los Viñedos, y otras mas Allá están entre muy bien y soberbiamente pensadas y equipadas para atender los visitantes. En torno a Bento Gonçalves hay uma óptima señalización de las rutas del vino entre las bodegas visitables, que no son pocas e incluyen uma vital tradición cultural y gastronómica del nortede Itália difusa em toda la Sierra Gaúcha. Em matéria de turismo vinícola estas bodegas, orientadas casi exclusivamente al vasto mercado interno, están a la vanguardia en Sudamérica. ${ }^{26}$

Apesar desses aspectos positivos, a região ainda não está adequadamente preparada para atender os turistas de forma correta, comportando desde deficiências de infra-estrutura até a inexistência da preocupação com o visitante, que não é um simples consumidor de vinhos. Segundo Pacheco e Silva (2001: 333):

Ainda é deficiente a assessoria prestada a esses turistas e são poucos os profissionais capacitados a orientá-los. Assim, as visitas às vinícolas acabam sendo precárias e marcadas, sobretudo, pelo interesse comercial, sem que haja uma maior preocupação dos guias e das empresas em prestar informações e aumentar o conhecimento do turista sobre vinho.

A principal rota de vinhos do Brasil é o Vale dos Vinhedos, localizado na Serra Gaúcha. Esta região conseguiu o selo de Indicação de Procedência (IP) Vale dos Vinhedos, o primeiro estudo de demarcação geográfica no Brasil. Isso é importante, pois facilita a aceitação do produto do mercado nacional e estrangeiro, considerando que o vinho que recebe este selo possui uma identidade particular, como aroma, sabor e cor, e as uvas têm de ser obrigatoriamente dessa região, não apenas das vinícolas do local. Embora as pequenas cantinas tenham se profissionalizado, investindo em tecnologia e se tornando vinícolas renomadas internacionalmente, não esqueceram a história de seu povo. Com a melhoria dos acessos, da sinalização e do paisagismo, com a construção de hotéis e pousadas e com o

26. "De frente com o enoturismo, as vinícolas do Vale dos Vinhedos, e outras mais além, estão entre as mais equipadas e planejadas para atender os visitantes. Ao redor de Bento Gonçalves existe uma ótima sinalizaçāo das rotas de vinho entre as cantinas que podem ser visitadas, que não são poucas e incluem uma tradiçāo cultural e gastronômica do norte da Itália, difundida em toda a Serra Gaúcha. Em matéria de turismo vinícola, essas cantinas, voltadas quase que exclusivamente ao vasto mercado interno, são vanguardas na América do Sul” (tradução da autora). aprimoramento dos restaurantes, o local que antes vivia o turismo associado a Gramado e Canela agora ganha vida própria.

De acordo com Splendor (2003: 35):

O visitante, para qualquer região a que se destina, no Brasil, encontrará em alguns locais mais, em outros menos, a presença do produto da videira. Mas não é em todos os Estados que desfrutará dos vastos panoramas formados de vinhedos em vales e colinas verdejantes.

O Vale dos Vinhedos é composto por inúmeras cantinas. Uma das principais é a Casa Valduga. Um dos proprietários, João Valduga, afirmou em entrevista in loco, realizada em 15 de maio de 2004, que a enogastronomia é fruto da natureza somada à tecnologia somadas, ainda, ao equipamento. Essa atividade, que está despontando no mundo, é muito importante para valorizar vinhos elaborados com altos padrões de excelência, buscando a harmonização do alimento ao vinho que acompanhará a refeição.

A Casa Valduga é uma das pioneiras no enoturismo no Brasil, pois desde meados de 1980 começou a receber grupos para jantar entre as pipas. A idéia se desenvolveu e hoje a vinícola possui pousadas, restaurantes, espaços próprios para degustação, cursos e locais para que o turista participe da colheita, sem perder, no entanto, a tradição. Exemplo disso acontece na vindima, quando um grupo de turistas visita a cantina para participar do processo de fabricação do vinho. Após auxiliarem na colheita, acompanham o esmagamento das uvas, sendo que este é feito conforme manda a tradição: o mais velho começa a esmagar as uvas com os pés neste caso, é o "nôno Valduga" (Luiz Valduga) -, para que depois os demais continuem o processo. Atualmente os investimentos estão voltados para o projeto do parque temático, que além da adega abrigará o varejo com capacidade de atendimento para 300 pessoas, uma sala de convenções com capacidade para 200 pessoas, um restaurante com padrão internacional e a construção de uma quarta pousada. ${ }^{27}$

A Cordelier dispõe de ampla estrutura enoturística, possibilitando ao turista visitar a cantina, as caves, a loja de vinhos, fazer degustação e passear em meio aos parreirais que cercam a empresa. Essa cantina registrou em 2003 o recebimento de 65.147 visitantes, sendo 1.549 excursões e 33.029 particulares. Como comparativo, no mês de janeiro de 2003 a vinícola recebeu 4.810 turistas; em 2004, esse número subiu para 7.960 pessoas, um incremento de $47 \%$. O mês de maior movimentação em 2003 foi julho, recebendo 11.274 visitantes. Para julho deste ano, a Cordelier projeta um crescimento de $50 \% .^{28}$

27. Informaçōes obtidas durante visita técnica realizada na Casa Valduga, no dia 22 de maio de 2004 28. Extraído do Jornal Vale dos Vinhedos, março/2004, ano 2, número 16 
Outra cantina localizada no Vale dos Vinhedos é a Vallontano, que está en trando aos poucos na atividade turística. Em entrevista realizada no dia 24 de maio de 2004, um dos proprietários da vinícola, Giovani Valduga, estudante de turismo da Universidade de Caxias do Sul, disse que atualmente a preocupação não é apenas com a uva e com o vinho, mas também com o turista. Embora a vinícola seja simples e pequena, conserva aparência de cantina familiar. Além de gerar empregabilidade no período da safra, a Vallontano faz exposições com artistas locais. Embora não possuam controle dos visitantes, apontam que a maior parte do público é de Porto Alegre e São Paulo. Ainda segundo Giovani, a divulgação do enoturismo não está sendo bem focada, pois muitas pessoas visitam as cantinas com o intuito de beberem à vontade, e não de realizarem turismo de fato.

Atualmente, o projeto enoturístico que está em fase de construção - orçado em 15 milhões de reais - é o Spa do Vinho, localizado também no Vale dos Vinhedos. Este é o segundo hotel do gênero no mundo, sendo que o primeiro está localizado na França, o Les Sources de Caudalie, pertencente ao Chateau Smith-Haut-Lafitte, em Bordeaux. Além de oferecer uma clínica de tratamentos de beleza regados à bebida, o Spa do Vinho colocará à disposição do público vinhos, geléias e sucos da região, aumentando a lucratividade de pequenos produtores locais. Segundo o cosmetólogo Alberto Kurebayashu, graças aos polifenóis que o compõem (resveratrol, catequinas, taninos e proantocianidinas), "o vinho combate os radicais livres que ameaçam destruir as fibras de colágeno e de elastina." ${ }^{29}$

O projeto está sendo concretizado pela união de algumas empresas, entre elas uma das mais importantes vinícolas do País: a Vinícola Miolo, que além dos vinhos produzidos no Vale dos Vinhedos, expandiu sua produção para o Vale do São Francisco (região de Pernambuco). ${ }^{30}$

Praticamente todas as cantinas do Vale dos Vinhedos possuem certa estrutura para receber turistas, ou seja, uma sala de degustação, além de oferecer as visitações pelo estabelecimento. Segundo a Associação dos Produtores de Vinhos do Vale dos Vinhedos - AProvale, o número de visitantes às empresas associadas cresceu $22 \%$ no ano passado em relação a 2002. Em 2001, receberam em torno de 60 mil turistas, número que passou para 100 mil em 2003. Para Jaime Milan, diretor-executivo da entidade, um dos motivos para o incremento na demanda foi a criação e a divulgação de um calendário anual de atividades vinculadas ao vinho, evitando a concentração em períodos como julho, em função do inverno, ou janeiro, devido à colheita. ${ }^{31}$

29. Disponívelem: <http://www.saude.abril.com.br/aberto/extra/227/vinho $>$. Acesso em: 22 set. 2003. 30. Informaçōes obtidas durante visita técnica à Vinícola Miolo, em Bento Gonçalves, Rio Grande do Sul, no dia 15 de maio de 2004.

31. Disponívelem:<http://www.vinhomagazine.com.br/ed50_enoturismo>.Acesso em: 28 mai. 2004.
O Vale dos Vinhedos está organizando o calendário anual de eventos, relacionando épocas de cultivo da uva, fabricação do vinho e datas festivas já comemoradas, como é o caso da Páscoa. Um dos eventos do Vale, realizado neste ano, foi o Festival da Colheita, que, segundo a APROVALE, recebeu a visita de 18 mil pessoas de diferentes partes do País. Os turistas participaram de diversas atividades, desde o esmagamento da uva com os pés até cursos de degustação e jantares típicos.

Localizada no distrito de Pinto Bandeira, pertencente à cidade de Bento Gonçalves, RS, a Rota Vinhos de Montanha é uma iniciativa entre as vinícolas da região, que formaram a Associação dos Produtores de Vinho de Pinto Bandeira, a ASPROVINHO. As vinícolas dessa região optam por uma produção em menor escala, dando ênfase à qualidade. O local oferece, além das degustações de vinhos, pousadas aconchegantes, passeios e farta gastronomia italiana, chegando a receber 60 mil turistas por ano. ${ }^{32}$

Paralelamente aos esforços dos cantineiros das rotas Vale dos Vinhedos e Vinhos de Montanha, a Vinícola Salton também está investindo no enoturismo, desenvolvendo a Rota Vale das Antas. De acordo com entrevista concedida à revista Veja, o presidente da empresa, Ângelo Salton, afirmou que a nova cantina, localizada em Tuiuty, Bento Gonçalves, terá como objetivo o aumento da produção e a criação de um parque temático que dará origem ao novo negócio da vinícola: o Turismo de Vinhos, que, segundo Lethbridge (2003: 65)

[...] como ocorre em vinícolas européias, os turistas poderāo passear entre os parreirais. De uma passarela a 3 metros de altura, dentro da cantina, eles acompanharāo todo o processo de produçāo do vinho, feito em maquinário de última geração.

Um dos eventos de maior prestígio no mundo dos vinhos é a Festa Nacional do Vinho - FenavinHo, realizada no Parque de Eventos de Bento Gonçalves. As festas anteriores aconteciam no mês de julho; já a FENAVINHO 2005 aconteceu entre os dias 28 de janeiro e 13 de fevereiro, paralelamente ao período de colheita. Segundo o presidente da XII edição da festa, Paulo Geremia, "devido à época, a FENAVINHO contemplará a colheita, enaltecendo ainda mais o enoturismo na região."33 Outra importante festa desse segmento é a Festa da Uva, realizada no município de Caxias do Sul, que na edição de 2001 recebeu mais de 200 mil visitantes.

32. Disponível em: <http://www.vjs.com.br/ortopedia/bento.htm\#pintobandeira>. Acesso em: 12 jun. 2004.

33. Disponível em: <http://www.viadelvino.com.br>. Acesso em: 18 jun. 2004 
Localizada no município de Garibaldi, distante 10 quilômetros de Bento Gonçalves, a Rota dos Espumantes se consolida como a principal localidade produtora de vinhos espumantes do País, sendo responsável por $80 \%$ da produção, seja pelo método champenoise (a fermentação ocorre na garrafa) ou charmat (a fermentação acontece em grandes recipientes). Aspectos culturais, arquitetônicos, gastronomia e música recebem a atenção dos turistas, simultaneamente às visitações a cantinas e degustações de vinhos e queijos. ${ }^{34}$

Além das rotas citadas, o Rio Grande do Sul comercializa o roteiro dos Vinhos dos Altos Montes, localizado em Flores da Cunha. Das doze vinícolas da rota, e que fazem parte da Associação de Produtores de Vinhos dos Altos Montes - APROMONTES, apenas cinco estão recebendo turistas. Esse roteiro foi criado em 2003, sendo a região considerada a maior produtora de vinhos do Brasil (Anuário Brasileiro da Uva e do Vinho, 2004).

Outra cidade da Serra Gaúcha que elaborou sua rota de vinhosé Veranópolis, conhecida como Terra da Longevidade, pois sua população atinge a maior expectativa de vida do País. Existem alguns estudos sobre a influência do vinho nessa particularidade, o que foi aproveitado para implementar a Rota Vinhos e Longevidade, abrangendo sete vinícolas (Anuário Brasileiro da Uva e do Vinho, 2004).

No ritmo dos investimentos que estão sendo realizados nas rotas de vinhos da Serra Gaúcha, governo do Estado de Pernambuco também está desenvolvendo seu pólo vitivinícola e, para tal, assumiu o compromisso de criar uma rota de apoio turístico, a Estrada da Uva e do Vinho. São 72 quilômetros de rodovia às margens do rio São Francisco, onde estão sendo instaladas 28 fazendas especializadas no cultivo da vinha, bem como duas adegas. ${ }^{35}$

O enoturismo deve atrair um público diversificado. Além dos turistas da própria região, as vinícolas do Vale do São Francisco contarão com um bom fluxo de cariocas e paulistas, principalmente por oferecer roteiros diferentes dos disponíveis no Rio Grande do Sul e Santa Catarina, tradicionais produtores de vinhos brasileiros. As estimativas são de que cada visitante gaste por dia $\mathrm{R} \$ 250,00$, apenas com hospedagem e alimentação. ${ }^{36}$

Por intermédio da Secretaria de Desenvolvimento Econômico, Turismo e Esportes, os projetos voltados ao enoturismo na região estão ganhando apoio,

34. Disponível em: $<$ http://www.serrars.hpg.ig.com.br/garibaldi.htm>. Acesso em: 18 jun. 2004.

35. Disponivel em: <http://www.pernambuco.gov.br/jornal_de_pernambuco/outubro/emais4.htm $>$. Acesso em: 12 jun. 2004

36. Idem. aproveitando a vantagem de que no Vale do São Francisco é possível colher mais de duas safras por ano, devido às condições climáticas e de solo. ${ }^{37}$

Na visão da enóloga Mônica Rossete, o comprometimento dos envolvidos é tamanho que no processo de fabricação do vinho que, "[...] temos a responsabilidade de extrair a verdade que está escondida na vinha e no seu fruto, a uva, e através dos processos de elaboração, revelar a sua qualidade e complexidade no vinho."38

É por causa desse empenho e comprometimento que a bebida vem ganhando espaço entre os brasileiros e oportunizando ao enoturismo uma forma de resgatar aspectos culturais capazes de atrair e, pasme!, superar as expectativas do turista.

\section{Considerações finais}

A atividade enoturística, acompanhando a lógica dos demais segmentos turísticos, necessita de um adequado planejamento e desenvolvimento sustentável, ou seja, comprometido com a comunidade e suas peculiaridades, e com o meio ambiente. $\mathrm{O}$ crescimento de forma desordenada não será capaz de satisfazer o turista, comprometendo a qualidade dos serviços prestados, a caracterização da cultura do povo e até mesmo a nobreza e o paladar do vinho.

Conforme abordado durante a pesquisa, embora a produção de vinhos remeta à Antiguidade, o enoturismo é bastante recente, o que deve ser avaliado como um aspecto positivo, visto que o turismo está sendo cada vez mais estudado e respeitado, oportunizando a esse segmento a chance de ser adequadamente planejado, em vez de ser banalizado. Por outro lado, o escasso material bibliográfico encontrado especificamente sobre o tema, sobretudo no Brasil, faz com que percebamos o empirismo com que o enoturismo está sendo executado; a falta de profissionalismo e planejamento.

Por meio das visitações a algumasvinícolas da Serra Gaúcha foi possível detectar inúmeras falhas nesse segmento, cuja demanda vem aumentando a cada safra de uvas e vinhos. A falta de informações e de dados sobre os turistas dificulta o planejamento da atividade; a falta de organização por parte das vinícolas nacionais impede uma melhor caracterização do enoturismo no País, bem como de sua demanda.

Apesar dos pontos negativos encontrados para que o enoturismo se consolide como atividade turística no País, seus benefícios à região produtora são indiscutíveis. Seu cuidado com o meio ambiente e com os indivíduos da comunidade

37. Disponível em http://www.destinopernambuco.com.br. Acesso em: 28 maio 2004

38. Extraído do folder da Vinícola Lídio Carraro Ltda., Bento Gonçalves, RS. 
proporcionam não apenas o cultivo da uva, mas principalmente o cultivo da cultura e das tradiçōes de um povo.

O Brasil possui um grande potencial enoturístico, mas necessita de um trabalho adequado para melhor desenvolvê-lo e desfrutá-lo como um todo, evitando ao máximo qualquer tipo de prejuízo à localidade e exercendo conceitos de sustentabilidade. No que tange à infra-estrutura receptora, na maior parte das rotas de vinho já existentes constatou-se a falta de estabelecimentos comerciais que possam atender às necessidades dos turistas com um nível de qualidade à altura das vinícolas.

Por fim, o enoturismo se apresenta como eficaz alternativa econômica, social e cultural em diferentes regiōes do planeta, desde que estas estejam preparadas para a vitivinicultura e para o turismo. A primeira ação depende de fatores naturais que muitas vezes não podem sofrer interferência do ser humano; a segunda, por outro lado, lida com o ser humano e seus desejos, buscando a satisfação ao entrar no mundo do vinho.

\section{Referências bibliográficas}

BRAGA, Danio \& ALZER, Célio. 2003. Tradiçāo, conhecimento e prática dos vinhos. 7. ed. Rio de Janeiro: José Olympio: ABS.

GUIA de Viñas, Bodegas y Viños de America del Sur. 2004. Buenos Aires: Austral Spectator.

GUIA de Viños de Chile 2001. Santiago: Paula Comunicaciones S.A.

HALL, C. Michael, et al. 2000. Wine tourism around the world. Estados Unidos: BetterworthHeinemann.

PACHECO, Aristides de Oliveira \& SILVA, Siwla Helena. 2001. Iniciação à enologia. In: ANSARAH, Marília Gomes dos Reis (Org.). Turismo: como aprender, como ensinar, 2. ed. São Paulo: SENAC-SP. p. 331-352.

_. Vinhos e uvas: guia internacional com mais de 2.000 citaçōes. 2003. 3. ed. São Paulo:

PACHECO, Aristides de Oliveira. 1995. Iniciaçāo à enologia. São Paulo: SENAC-SP.

SPLENDOR, Firmino. 2003. Vinho - degustação e serviço, saúde, enoturismo - licores. Caxias do Sul, RS: EDUCS.

ZINGARELLI, Nicola. 2002. Vocabolario della lingua italiana. Itália: Zanichelli.

\section{Periódicos}

ANUÁRIO Brasileiro da Uva e do Vinho. Santa Cruz do Sul: Editora Gazeta Santa Cruz, 2004. Jornal Vale dos Vinhedos, Março/2004, ano 02, número 16.
LETHBRIDGE, Tiago. O homem que nāo entendia de vinho. Revista Exame, São Paulo, p. 62-65, 12 nov. 2003.

\section{Sites}

Associação dos Produtores de Vinhos Finos do Vale dos Vinhedos: http://www.valedosvinhedos. com.br. Acesso em: 29 mai. 2004

Banco do Brasil: http://www.bb.com.br/noticias. Acesso em: 31 mai. 2004

Departamento do Governo de Queensland para oDesenvolvimento Estadual: http://www.sd.qld. gov.au/dsdweb/htdocs/global/content.cfm. Acesso em: 1 jun. 2004.

Indústria de Vinhos da Austrália: http://www.wfa.org.au/projectos/winetourism.html.

Instituto Brasileiro do Vinho: http://www.ibravin.org.br.

Instituto de Turismo de Portugal: http://www.ifturismo.min-economia.pt.

Movimento de Turismo del Vino: http://www.movimentoturismovino.it.

http://www.planetavino.com/navegacion/navegar. Acesso em: 28 mai. 2004.

Movimento de Turismo del Vino de Lombardia: http://www.mtvlombardia.it. Acesso em: 2 jun. 2004.

Portal Girus: http://www.girus.com.br/viagens/conceitos.php. Acesso em: 4 jun. 2004

http://www.vinealis.com/canales.

VinhoMagazine: http://www.vinhomagazine.com.br/ed50_enoturismo. Acesso em: 28 mai. 2004.

http://www.nolasco.cjb.net. Acesso em: 16 mai. 2004.

http://www.planetavino.com/navegacion/navegar. Acesso em: 28 mai. 2004.

http://www.revistadigital.com.br/empresas.asp. Acesso em: 11 jun. 2004.

http://www.ivv.min-agricultura.pt/cultura/files/rotas.html. Acesso em: 28 mai. 2004.

http://www.saude.abril.com.br/aberto/extra/227/vinho. Acesso em: 22 set. 2003.

http://www.viadelvino.com.br. Acesso em: 18 jun. 2004.

http://www.vjs.com.br/ortopedia/bento.htm\#pintobandeira. Acesso em: 12 jun. 2004.

http://www.serrars.hpg.ig.com.br/garibaldi.htm, acesso em 18 jun. 2004.

http://www.pernambuco.gov.br/jornal_de_pernambuco/outubro/emais4.htm.

http://www.destinopernambuco.com.br. Acesso em: 28 mai. 2004.

Recebido em: 04/07/2005.

Aprovado em: 18/07/2005. 